\title{
Dyadic incongruence in chronic heart failure: implications for patient and carer psychosocial health and self-care
}

\begin{abstract}
Aim and objectives. To examine whether chronic heart failure (CHF) patient-carer dyads who disagree about the division of illness management tasks (incongruent) experience poorer psychosocial health and self-care, than those who agree (congruent).
\end{abstract}

Background. Informal carers often assist patients with (CHF) in the complex management of their illness but little is known about how relationship dynamics may affect psychosocial health. Design. A prospective cross-sectional study was adopted with a purposeful sample of $25 \mathrm{CHF}$ patient-carer dyads residing in Australia.

Methods. Data were collected via mail-out questionnaires. Dyads were classified as congruent or incongruent using the Heart Failure Care Assessment Scale. Depression, anxiety, stress, and quality of life were assessed in patients and carers. Additionally, self-care and relationship quality were assessed in patients; and burden and esteem were assessed in carers. Differences in congruent and incongruent patient and carer outcomes were examined.

Results. Dyads were predominantly spousal and around a third demonstrated incongruence. No significant differences were found between congruent $(n=16)$ and incongruent $(n=9)$ dyads, though patients in incongruent dyads tended to have been diagnosed more recently.

Conclusion. In CHF patient-carer dyads incongruence exists even for patients with relatively mild CHF heart failure symptoms. These findings indicate that dyadic incongruence in illness management might not affect high-functioning CHF heart failure patients or their carers.

Relevance to clinical practice. Given the prevalence of dyadic incongruence and the possibility of further negative outcomes with disease progression, it is important to examine factors such as length of time since diagnosis or type of carer relationship. By implementing self-care education and management strategies that focus on the dyad, rather than the individual, nurses have the potential to improve both patient and carer outcomes.

Key words: carer; heart disease; management; patient-centered care; psychosocial adjustment, self-care

This is the author manuscript accepted for publication and has undergone full peer review but has not been through the copyediting, typesetting, pagination and proofreading process, which may lead to differences between this version and the Version of Record. Please cite this article as doi: $\underline{10.1111 / \text { jocn.13836 }}$

This article is protected by copyright. All rights reserved 


\section{What does this paper contribute to the wider global clinical community?}

- Confirms the high prevalence of dyadic incongruence in the patient with CHF failure and carer relationship

- Identifies the need for examination of the impact of patient carer incongruence on psychosocial health across the spectrum of CHF severity

- Compared to individual-level approaches to HF self-care and education, dyadic nursing approaches have the potential to improve health-outcomes for both members of the dyad; patient and carer

\section{$\bullet$ \\ INTRODUCTION}

Chronic heart failure (CHF), a complex and changeable condition, affects around 23 million people worldwide and its prevalence increases with age (Bui et al. 2011). Those people affected must complete a range of self-care behaviors to manage symptoms and maintain medical stability (Riegel et al. 2011a, Riegel et al. 2011b, Moser et al. 2012). In many cases, a family member or friend takes on the role of informal carer and assumes responsibility for particular aspects of CHF management (Vellone et al. 2014a). Subsequently, role changes within existing relationships often impose additional strains on relationships. Preliminary evidence suggests that in a large proportion of cases, perceptions of the presence and severity of CHF symptoms differ between the patient with CHF and their carer (Quinn et al. 2010, Pressler et al. 2013, Cameron et al. 2016). Moreover, many patient-carer dyads disagree about who should (and who does) take primary responsibility for different aspects of CHF care (Retrum et al. 2013, Buck et al. 2013b).

\section{Dyadic incongruence}

This disagreement between patients with CHF and their carers regarding illness management is termed dyadic incongruence. It has been suggested that dyadic incongruence could lead to poorer adherence to medical recommendations and ultimately to worsening of CHF symptoms and quality of life (Buck et al. 2013a). In other groups affected by chronic illnesses such as cancer, incongruence between patients and their carers appears to negatively affect disease management and patients' psychological health (Clipp \& George 1992, Miaskowski et al. 1997). 
Incongruence may also negatively impact the health and quality of life of carers. It has been established that, as a group, informal carers of patients with CHF experience relatively poor quality of life and low general wellbeing (Kang et al. 2011, Whittingham et al. 2013). They often struggle with the changes they must make in their lives due to adopting the added responsibilities of being a carer (Luttik et al. 2007, Humphrey et al. 2013, Ahldén et al. 2014). Disagreement relating to illness management may contribute to carer stress, although little research has been directed towards developing nursing interventions that target the health of both members of the dyad.

Improved understanding of dyadic incongruence has the potential to inform clinicians in developing nursing interventions that not only allow for individualized educational approaches to promote engagement in the recommended rigorous CHF self-care strategies, but would also enable therapeutic conversations aimed at improving the psychosocial health for both members of the dyad (Bell 2013). At present there is little research investigating the effects of dyadic incongruence in $\mathrm{CHF}$ caring relationships. Evidence from initial qualitative studies suggests that incongruence is related to increased conflict and stress (Retrum et al. 2013, Kitko et al. 2014). However, dyadic incongruence has not yet been examined quantitatively. As such, it is not clear whether it is related to other important outcomes such as self-care skills, perceived burden, anxiety or quality of life.

\section{METHODS}

\section{Study design}

This was a prospective cross-sectional study that examined the association between CHF illness management incongruence in the dyadic patient-carer relationship and psychosocial health comprising depression, anxiety, quality of life, relationship quality, burden and self-care. Chronic heart failure patients were recruited from a multidisciplinary disease management program and a heart failure rehabilitation program at a metropolitan-based major tertiary hospital. Chronic heart failure patient and carer dyads were eligible for the study if both members of the dyad were: (a) over 18 years old; (b) had sufficient literacy skills to complete the questionnaires; (c) had not been diagnosed with dementia; and (d) were not living in an agedcare facility. Patient-carer relationships were categorized as either congruent or incongruent and 
relationship quality, psychosocial health of patients and carers and self-care skills of patients were then compared across the two groups.

\section{Procedures}

Consenting participants were asked to provide contact details of an informal caregiver involved with their day-to-day care outside hospital. Patients' medical records were reviewed to confirm a diagnosis of CHF. All other information was collected via questionnaires. Questionnaire packs were posted out separately to patients and their carers, and participants were instructed to complete them independently.

\section{Ethical considerations}

Ethics approvals (HREC-A 031/32) were obtained from the Eastern Health Human Research Ethics Committee and the Australian Catholic University Human Research Ethics Committee. All participants received written documentation detailing the purpose of the study and potential risks and benefits, and gave consent to participate. Signed informed consent was obtained prior to data collection. Participation in the study was voluntary, confidentiality was assured and the data were rendered anonymous. The study conformed to the principles outlined in the Declaration of Helsinki (World Medical Association 2013).

\section{Measures}

\section{Patient and carer measures}

Demographic information. Information was collected about basic demographics, medical visits in the past month, the date of the $\mathrm{CHF}$ diagnosis and previous treatment for mental health issues.

Dyad type. The Heart Failure Care Assessment Scale (HFCAS) is a valid means for categorizing dyadic care types (Buck et al. 2013b). Participants were asked to select one of four descriptors that best represented the care arrangement in their dyad: patient-oriented; caregiveroriented; collaboratively oriented; or complementarily oriented. Selections were compared for each dyad; patients and carers who had selected the same descriptor were categorized as congruent while those who selected different descriptors were incongruent. 
Depression and anxiety. The Depression Anxiety Stress Scales (DASS) (Lovibond \& Lovibond 1995) short version (21 items) provides a measure of depression, anxiety and stress symptoms experienced during the previous week. Each item is scored on a four point scale ranging from zero (did not apply to me) to three (applied to me very much, or most of the time). Higher scores indicate greater severity of symptoms common to anxiety and depression. For example, normative scoring ranges for depression severity are: 0-9 = normal (no symptoms); 1013 mild; $14-20$ moderate; 21-27 severe. The DASS is widely used and has been reported to have high internal reliability on each subscale: $\alpha=0.91$ for depression; $\alpha=0.80$ for anxiety; and $\alpha=$ 0.84 for stress (Sinclair et al. 2012).The DASS also has sufficient construct, convergent and divergent validity (Henry \& Crawford 2005).

Quality of life. Patients and carers each rated their perceived quality of life using Cantril's (1965) 10-point Self-Anchoring Striving Scale; higher scores indicated higher perceived quality of life. This scale has been used extensively in the general population and in heart failure populations (e.g. Jaarsma et al. 2005, Hoekstra et al. 2011).

\section{Patient-only measures}

CHF symptom severity. Patients completed a CHF symptom checklist, and the severity of symptoms was then classified using the New York Heart Association (NYHA) classification (Criteria Committee New York Heart Association 1964). Scores range from I (no limitation of physical activity) to IV (unable to carry out any physical activity without discomfort).

Relationship quality. The Revised Dyadic Adjustment Scale (RDAS) (Busby et al. 1995) is a validated assessment tool which measures three aspects of relationship quality: consensus; satisfaction; and cohesion. It was used to assess patients' perception of the quality of their relationship with their carer. Items specific to intimate partnerships were excluded because some dyads consisted of non-spousal relationships, however the three subscales were maintained: dyadic consensus (four items); dyadic satisfaction (two items); and dyadic cohesion (four items). Responses were made on five- or six-point scales. The internal reliability of the altered scale was adequate for consensus $(\alpha=.53)$ and satisfaction $(\alpha=.68)$ and was excellent for cohesion $(\alpha=$ $.86)$. The overall reliability of the measure was excellent $(\alpha=.80)$.

Self-care expertise. The Self-Care Heart Failure Index (SCHFI) (Riegel et al. 2004) assessed patients' level of self-care expertise using 22 items that formed three scales: self-care maintenance (ten items on four-point scales), self-care management (five items on four- to six- 
point scales), and self-care confidence (six items on four-point scales). The management score was only calculated for patients who reported symptoms in the past month; higher scores indicated better self-care with scores above 70 considered adequate (Riegel et al. 2009a). Adequate to good internal reliability and validity of the three self-care scales have been demonstrated (Riegel et al. 2009b).

\section{Carer-only measure}

Carer burden and esteem. The Caregiver Reaction Assessment (CRA) (Given et al. 1992) measures positive and negative reactions of carers of elderly people with physical or mental impairments. It consists of 24 items, which make up five subscales: impact on schedule; lack of family support; impact on health; impact on finances; and caregiver esteem. An average score was calculated for each subscale, with a possible score range of one to five. Higher scores on caregiver esteem indicated more positive caregiving experiences, whereas higher scores on the other four subscales indicated more negative caregiving experiences (Whittingham et al. 2013). The subscales have been demonstrated to have good internal reliability and validity (Given et al. 1992).

\section{Analysis}

Normally distributed variables were described using the mean $(M)$ and standard deviation $(S D)$, and were compared using t-tests with Levene's test of equality of variance. Non-normally distributed variables were described using the median (Mdn) and interquartile range (IQR) and were compared using Mann-Whitney U tests. Categorical variables were compared using chisquare with Fisher's exact test when cell numbers were $<5$. Differences were considered significant at $p<0.05$. Effect size was calculated as $r=z / \sqrt{ } \mathrm{N}$ (Fritz et al. 2012). Missing data $(<5 \%)$ in the CRA were replaced with the participant's average score in the subscale containing the unanswered item(s) (Nijboer et al. 1999).

\section{Results}

As a group, the CHF patients were relatively healthy, with three-quarters within NYHA class I or II (Table 1). Only 8\% reported making an unscheduled appointment with their general practitioner in the previous month, and most (80\%) reported no history of depression or anxiety, rating their quality of life as high. The length of time since diagnosis ranged from 2 weeks to 14 
years $(\mathrm{Mdn}=15$ months, $\mathrm{IQR}=51.5)$. On average, patients scored in the normal range for current depression, anxiety and stress symptoms, but reported slightly inadequate self-care, scoring on average below the suggested cut-off score of 70 for maintenance, management and confidence. Patients rated their overall relationship quality with the carer as moderate.

The majority of carers were female and not working (Table 1). All but one of the carers was a close family member of the CHF patient; most dyads (78\%) were in a spousal relationship with only two a child-parent relationship. On average, partners in the dyads had known each other for 46 years. Most participants were born in Australia (62\%) and identified English as their first language (96\%). Further demographic information for the 25 patients and carers is provided in Table 1. On average, carers reported low levels of anxiety and stress and marginal levels of depression symptoms. Their quality of life was reasonably high. Carers experienced low levels of burden related to their caregiving responsibilities and experienced relatively high levels of esteem linked to their role as carer.

\section{Dyad-type distribution}

Around a third of dyads were categorized as incongruent (Table 2). Patients in congruent dyads tended to have been diagnosed with $\mathrm{CHF}$ for longer $(\mathrm{Mdn}=30$ months, IQR=94) than patients in incongruent dyads $(\mathrm{Mdn}=13$ months, $\mathrm{IQR}=13.25)$. This difference equated to a moderate effect size $(r=-0.38)$, but was not statistically significant $(U=28, p=0.09)$.

\section{Congruent versus incongruent dyads}

There were no significant differences in depression, anxiety, quality of life or self-care for patients in congruent versus incongruent care relationships (Table 3). For relationship quality there was a marginally significant difference for relationship satisfaction only; patients in congruent dyads indicated higher satisfaction than those in incongruent dyads.

Carers in congruent dyads did not differ significantly from carers in incongruent dyads in terms of their psychosocial functioning, quality of life or carer esteem (Table 4). However, there was a marginally significant effect for an aspect of carer burden. Specifically, carers in 
incongruent dyads reported a slightly higher (more negative) impact on their health compared with carers in congruent dyads.

\section{DISCUSSION}

This is the first study to compare psychosocial health and self-care in congruent versus incongruent $\mathrm{CHF}$ patient-carer dyads using quantitative methods. In this sample of predominantly spousal dyads around a third demonstrated incongruence. That is, they disagreed about which member in the dyad was primarily responsible for the patient's CHF management. Although similar or higher levels of incongruence have been observed in CHF populations with more severe levels of illness (Retrum et al. 2013; Buck et al. 2013a, Buck et al. 2013b, Kitko et al. 2015), this is the first study to identify that dyadic incongruence may be common in patients with lower disease severity (as per NYHA classification). We also found that patients among incongruent dyads tended to have been diagnosed with CHF more recently than patients in congruent dyads. This suggests that in the initial months after diagnosis, patients and their carers may still be adjusting to the change in their circumstances, and working out their new roles and responsibilities. However, with time and experience that leads to gaining greater confidence in managing CHF (Buck et al. 2015; Vellone et al. 2015b), patients and their carers may be able to reach a consensus about how to divide care responsibilities and have. Longitudinal research will be required to clarify the influence of temporal factors in dyadic agreement.

Contrary to expectations, in this relatively stable sample, incongruence was not associated with higher levels of anxiety or depression or with poorer quality of life, either for patients or for their carers. These results contrast with findings from qualitative studies that focused on patients with later-stage CHF and their carers, which found increased conflict and stress for incongruent dyads (Retrum et al. 2013, Kitko et al. 2015). It is notable that the mental health and quality of life of carers was relatively high in both congruent and incongruent groups, and while many studies have reported negative outcomes for carers of HF patients (Saunders 2009, Hwang et al. 2011, Harkness et al. 2013, Buck et al 2015, Chung et al. 2016), our findings align with other research that has demonstrated that when CHF patients have relatively good physical health, carers experience relatively low burden and anxiety, while their quality of life is generally high (Ågren et al. 2010, Pressler et al. 2013). Together, this evidence suggests that as a group, spousal carers of high-functioning CHF patients may be relatively resistant to the impact 
of incongruence. It may be that incongruence plays a more significant and negative role in advanced end-stage CHF, where there is an increased likelihood of vulnerability to adverse psychosocial outcomes by both patient and carer.

We observed a small, marginal difference in relationship satisfaction between congruent and incongruent dyads, suggesting that patients in incongruent dyads might be less satisfied with their relationship. Due to the cross-sectional nature of the study, the causal direction of this relationship is not clear. It may be that conflict or tension associated with incongruence had a negative impact on relationship satisfaction. Conversely, patient-carer dyads that had less satisfactory relationships to begin with may have had more trouble reaching consensus about CHF management roles and responsibilities after the diagnosis. Regardless of the direction of the association, other research has shown that better relationship quality has been associated with improved psychosocial and physical health outcomes among both members of the dyad across the CHF trajectory (Hooker et al. 2015). Thus, relationship quality generally, and dyadic congruence more specifically, should both be considered in future research investigating CHF outcomes.

Despite their relatively good health, patients in this sample reported marginally suboptimal self-care expertise. Inadequate self-care management of CHF is common, and contributes greatly to the burden experienced by both patients and the healthcare industry (Lee $e t$ al. 2011, Jones et al. 2012, McGreal et al. 2014). Informal carers play a significant role in CHF management (Vellone et al. 2014a), however their role is not always considered when specialists are supporting CHF patients with self-care (Liljeroos et al. 2014). This suggests there is an opportunity to improve disease management by developing more family-focused interventions that consider the health and well-being of both the patient with CHF and their caregiver. Cardiovascular nurses are well positioned to take such an approach, identifying and intervening when dyads are assessed as being incongruent and vulnerable to adverse psychological health and well-being (Lyons et al. 2016).

\section{Limitations}

This study was conducted on a relative small sample of 25 patient-carer dyads $(n=50)$, who were predominantly in spousal relationships. This being noted, these results will need to be confirmed with future research employing larger, more diverse samples of CHF dyads. Chronic Heart Failure is associated with ageing, and thus it is not uncommon for an adult child to become 
a primary carer for a patient with CHF (Bidwell et al. 2015, Lee et al. 2015). Considering that dyadic CHF care is a transactional process between the patient and carer where both members of the dyad interact within a naturalistic decision-making process (Buck et al. 2013a), it cannot be assumed that in other types of dyadic relationships the roles and relationships are necessarily equal. For example, research indicates that CHF patients who are not married report more negative outcomes (Dunbar et al. 2008), implying that spousal care relationships specifically are advantageous. Further research is therefore required to establish whether incongruence varies as a result of the various types of carer / patient relationships.

\section{Conclusion}

This study has corroborated recent findings that dyadic incongruence is common in CHF patients and carers, and has shown that incongruence exists even for patients with relatively mild $\mathrm{CHF}$ symptoms. However, we did not observe an association between incongruence and poor psychosocial health and self-care in these dyads, perhaps due to the high health status of the patients in this sample. Given the prevalence of dyadic incongruence, and the possibility of further negative outcomes with disease progression, it is important to develop and test individualized family nursing interventions aimed at improving the psychosocial health for both members of the CHF dyad. The quality of the relationship between a CHF patient and their informal carer is a modifiable variable which has potential to improve the management of the illness and reduce its impact on individuals and society and therefore deserves continued exploration. However, our findings suggest that relationship factors may be less important for relatively high functioning $\mathrm{CHF}$ patients. Future studies should examine whether factors such as length of time since diagnosis or type of carer relationship are significantly associated with dyadic functioning. This may provide family nurses with the opportunity to better target the timing and tailoring of patient education and counselling directed at self-care.

\section{Relevance to clinical practice}

Dyadic incongruence is common and has the potential to affect psychosocial outcomes in CHF patients and carers. In low functioning and recently diagnosed CHF, self-care education should take dyadic incongruence into consideration. In high functioning CHF patients, incongruence appears to be less important to patient and carer outcomes. Thus, rather than adopting individual- 
level approaches directed at the long-term disease management of $\mathrm{CHF}$, dyadic nursing approaches have the potential to result in enhanced health outcomes for both members of the dyad.

\section{DISCLOSURE}

The authors have confirmed that all authors meet the ICMJE criteria for authorship credit www.icmje.org/ethical_1author.html), as follows: (1) substantial contributions to conception and design of, or acquisition of data or analysis and interpretation of data, (2) drafting the article or revising it critically for important intellectual content and (3) final approval of the version to be published.

\section{REFERENCES}

Ågren S, Evangelista L \& Strömberg A (2010) Do partners of patients with chronic heart failure experience caregiver burden? European Journal Of Cardiovascular Nursing 9, 254-62.

Ahldén MK, Rönning H \& Ågren S (2014) Facing the unexpected - A content analysis of how dyads face the challenges of postoperative heart failure. Clinical Nursing Studies 2, 7483.

Bell JM (2013) Family nursing is more than family centered care. Journal of Family Nursing 19, 411-417.

Bidwell JT, Vellone E, Lyons KS, D'Agostino F, RiegeI B, Juárez-Vela R, Hiatt SO, Alvaro R \& Lee CS (2015) Determinants of heart failure self-care maintenance and management in patients and caregivers: A dyadic analysis. Research in Nursing \& Health 38, 392-402.

Buck HG, Mogle J, Riegel B, McMillan S \& Bakitas M (2015) Exploring the relationship of patient and informal caregiver characteristics with heart failure self-care using the ActorPartner Interdependence Model: Implications for outpatient palliative care. Journal of Palliative Medicine 18, 1026-32.

Buck HG, Kitko L \& Hupcey JE (2013a) Dyadic heart failure care types: Qualitative evidence for a novel typology. Journal of Cardiovascular Nursing, 28, E37-46. 
Buck HG, Zambroski CH \& Hupcey JE (2013b) Assessing the response of patients and spousal/partner caregivers to a new instrument measuring dyadic heart failure care types. European Journal of Cardiovascular Nursing 12, 209-13.

Bui AL, Horwich TB \& Fonarow GC (2011) Epidemiology and risk profile of heart failure. Nature Reviews Cardiology 8, 30-41.

Busby DM, Christensen C, Crane DR \& Larson JH (1995) A revision of the dyadic adjustment seale for use with distressed and nondistressed couples: Construct hierarchy and multidimensional scales. Journal of Marital and Family Therapy 21, 289-308.

Cameron J, Rhodes KL, Ski CF \& Thompson DR (2016) Carers' views on patient self-care in chronic heart failure. Journal of Clinical Nursing 25, 144-52.

Cantril, H. (1965). The pattern of human concerns. New Brunswick, NJ: Rutgers University Press.

Chung ML, Lennie TA, Mudd-Martin G, Dunbar SB, Pressler SJ \& Moser DK (2016)

Depressive symptoms in patients with heart failure negatively affect family caregiver outcomes and quality of life. European Journal of Cardiovascular Nursing 15, 30-8.

Clipp EC \& George LK (1992) Patients with cancer and their spouse caregivers. Perceptions of the illness experience. Cancer 69, 1074-9.

Criteria Committee of the New York Heart Association (1964) Diseases of the heart and blood vessels: Nomenclature and criteria for diagnosis. Boston, MA: Little, Brown.

Dunbar SB, Clark PC, Quinn C, Gary RA \& Kaslow NJ (2008) Family influences on heart failure self-care and outcomes. Journal of Cardiovascular Nursing 23, 258-65.

Fritz CO, Morris PE \& Richler JJ (2012) Effect size estimates: current use, calculations, and interpretation. Journal of Experimental Psychology: General 141, 2-18.

Given CW, Given B, Stommel M, Colllins C, King S \& Franklin S (1992) The Caregiver Reaction Assessment (CRA) for caregivers to persons with chronic physical and mental impairments. Research in Nursing and Health 15, 271-83.

Harkness K, Arthur H \& McKelvie R (2013) The measurement of uncertainty in caregivers of patients with heart failure. Journal of Nursing Measurement 21, 23-42.

Henry JD \& Crawford JR (2005) The short-form version of the Depression Anxiety Stress Scales (DASS-21): Construct validity and normative data in a large non-clinical sample. British Journal of Clinical Psychology 44, 227-39.

This article is protected by copyright. All rights reserved 
Hoekstra T, Lesman-Leegte I, van Veldhuisen DJ, Sanderman R \& Jaarsma T (2011) Quality of life is impaired similarly in heart failure patients with preserved and reduced ejection fraction. European Journal of Heart Failure 13, 1013-18

Hooker SA, Grigsby ME, Riegel B \& Bekelman DB (2015) The impact of relationship quality on health-related outcomes in heart failure patients and informal family caregivers: An integrative review. Journal of Cardiovascular Nursing 30, S52-63.

Humphrey L, Kulich K, Deschaseaux C, Blackburn S, Maguire L \& Strömberg A (2013) The Caregiver Burden Questionnaire for Heart Failure (CBQ-HF): Face and content validity. Health and Quality of Life Outcomes 11, 84.

Hwang B, Fleischmann KE, Howie-Esquivel J, Stotts NA \& Dracup K (2011) Caregiving for patients with heart failure: Impact on patients' families. American Journal of Critical Care 20, 431-42.

Jaarsma T, Halfens R, Abu-Saad H, Dracup K, Stappers J \& van Ree, J (1999) Quality of life in older patients with systolic and diastolic heart failure. European Journal of Heart Failure 1, 151-60.

Jones CD, Holmes GM, Dewalt DA, Erman B, Broucksou K, Hawk V, Cene CW, Wu JR \& Pignone M (2012) Is adherence to weight monitoring or weight-based diuretic selfadjustment associated with fewer heart failure-related emergency department visits or hospitalizations? Journal of Cardiac Failure 18, 576-84.

Kang X, LiZ \& Nolan MT (2011) Informal caregivers' experiences of caring for patients with chronic heart failure: Systematic review and metasynthesis of qualitative studies. Journal of Cardiovascular Nursing 26, 386-94.

Kitko LA, Hupcey JE, Pinto C \& Palese M (2015) Patient and caregiver incongruence in advanced heart failure. Clinical Nursing Research 24, 388-400.

Lee CS, Moser DK, Lennie TA \& Riegel B (2011) Event-free survival in adults with heart failure who engage in self-care management. Heart Lung 40, 12-20.

Lee CS, Vellone E, Lyons KS, Cocchieri A, Bidwell JT, D’Agostino F, Hiatt SO, Alvaro R, Buck HG \& Riegel B (2015) Patterns and predictors of patient and caregiver engagement in heart failure care: A multi-level dyadic study. International Journal of Nursing Studies 52, 588-97. 
Liljeroos M, Ågren S, Jaarsma T \& Strömberg A (2014) Perceived caring needs in patientpartner dyads affected by heart failure: A qualitative study. Journal of Clinical Nursing 23, 2928-38.

Locke DEC, Decker PA, Sloan JA, Brown PD, Malec JF, Clark MM, Rummans TA, Ballman KV, Schaefer PL \& Buckner JC (2007) Validation of single-item linear analog scale assessment of quality of life in neuro-oncology patients. Journal of Pain and Symptom Management 34, 628-38.

Lovibond SH \& Lovibond PF (Eds) (1995) Manual for the Depression Anxiety Stress Scales, Sydney: Psychology Foundation.

Luttik ML, Blaauwbroek A, Dijker A \& Jaarsma T (2007) Living with heart failure: Partner perspectives. Journal of Cardiovascular Nursing 22, 131-7.

Lyons KS, Vellone E, Lee CS, Cocchieri A, Bidwell JT, D’Agostino F, Hiatt SO, Alvaro R, Vela RJ, Riegel B (2015) A dyadic approach to managing heart failure with confidence. Journal of Cardiovascular Nursing 30, S64-71.

McGreal MH, Hogan MJ, Walsh-Irwin C, Maggio NJ \& Jurgens CY (2014) Heart failure selfcare interventions to reduce clinical events and symptom burden. Research Reports in Clinical Cardiology 5, 243-57.

Miaskowski C, Kragness L, Dibble S \& Wallhagen M (1997) Differences in mood states, health status, and caregiver strain between family caregivers of oncology outpatients with and without cancer-related pain. Journal of Pain and Symptom Management 13, 138-47.

Moser DK, Dickson V, Jaarsma T, Lee C, Strömberg A \& Riegel B (2012) Role of self-care in the patient with heart failure. Current Cardiology Reports 14, 265-75.

Nijboer C, Triemstra M, Tempelaar R, Sanderman R \& Van Den Bos GAM (1999) Measuring both negative and positive reactions to giving care to cancer patients: Psychometric qualities of the Caregiver Reaction Assessment (CRA). Social Science and Medicine 48, 1259-69.

Pressler SJ, Gradus-Pizlo I, Chubinski SD, Smith G, Wheeler S, Sloan R \& Jung M (2013) Family caregivers of patients with heart failure: A longitudinal study. Journal of Cardiovascular Nursing 28, 17-428.

Quinn C, Dunbar SB \& Higgins M (2010) Heart failure symptom assessment and management: Can caregivers serve as proxy? Journal of Cardiovascular Nursing 25, 142-8. 
Retrum JH, Nowels CT \& Bekelman DB (2013) Patient and caregiver congruence: The importance of dyads in heart failure care. Journal of Cardiovascular Nursing 28, 129-36.

Riegel B, Carlson B, Moser DK, Seburn M, Hicks FD \& Roland V (2004) Psychometric testing of the self-care of heart failure index. Journal of Cardiac Failure 10, 350-60.

Riegel B, Driscoll A, Suwanno J, Moser DK, Lennie TA, Chung ML, Wu JR, Dickson VV, Carlson B \& Cameron J (2009a) Heart failure self-care in developed and developing countries. Journal of Cardiac Failure 15, 508-16.

Riegel B, Lee CS, Dickson VV \& Carlson B (2009b) An update on the self-care of heart failure index. Journal of Cardiovascular Nursing 24, 485-97.

Riegel B, Lee CS, Albert N, Lennie T, Misook C, Eun Kyeung S, Bentley B, Seongkum H, Worrall-Carter L \& Moser DK (2011a) From novice to expert: Confidence and activity status determine heart failure self-care performance. Nursing Research 60, 132-38.

Riegel B, Lee CS \& Dickson VV (2011b) Self care in patients with chronic heart failure. Nature Reviews Cardiology 8, 644-54.

Rogers MP, Orav J \& Black PM (2001) The use of a simple Likert scale to measure quality of life in brain tumor patients. Journal of Neuro-Oncology 55, 121-31.

Saunders MM (2009) Indicators of health-related quality of life in heart failure family caregivers. Journal of Community Health Nursing 26, 173-82.

Sinclair SJ, Siefert CJ, Slavin-Mulford JM, Stein MB, Renna M \& Blais MA (2012)

Psychometric evaluation and normative data for the Depression, Anxiety, and Stress Scales-21 (DASS-21) in a nonclinical sample of U.S. adults. Evaluation and the Health Professions 35, 259-79.

Vellone E, Chung ML, Cocchieri A, Rocco G, Alvaro R \& Riegel B (2014a). Effects of self-care on quality of life in adults with heart failure and their spousal caregivers: testing dyadic dynamics using the Actor-Partner Interdependence Model. Journal of family nursing 20,120-41.

Vellone E, D'Agostino F, Buck HG, Fida R, Spatola CF, Petruzzo A, Alvaro R \& Riegel B (2014b) The key role of caregiver confidence in the caregiver's contribution to self-care in adults with heart failure. European Journal of Cardiovascular Nursing 14, 378-81. 
Whittingham K, Barnes S \& Gardiner C (2013) Tools to measure quality of life and carer burden in informal carers of heart failure patients: A narrative review. Palliative Medicine 27, 596-607.

World Medical Association (2013) World Medical Association Declaration of Helsinki: Ethical principles for medical research involving human subjects. Journal of the American Medical Association 310, 2191-4.
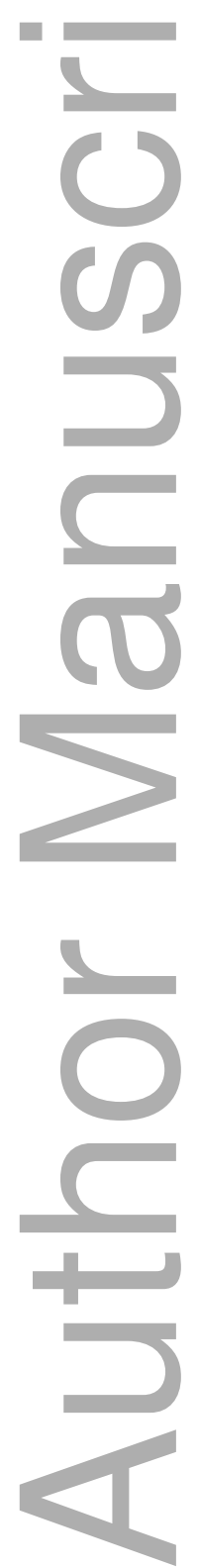
Table 1 Demographic characteristics of patients and carers

\begin{tabular}{|c|c|c|c|c|}
\hline \multirow[b]{2}{*}{ Dyad Member } & \multirow[b]{2}{*}{ Demographic } & \multicolumn{3}{|c|}{ Mean $(S D) / \mathrm{N}(\%)$} \\
\hline & & $\begin{array}{l}\text { All Dyads } \\
(n=25)\end{array}$ & $\begin{array}{l}\text { Congruent Dyads } \\
\qquad(\mathrm{n}=16)\end{array}$ & $\begin{array}{l}\text { Incongruent Dyads } \\
\qquad(\mathrm{n}=9)\end{array}$ \\
\hline \multirow{2}{*}{ CHF patient } & Age $(\text { years })^{a}$ & $73.28(9.92)$ & $73.94(9.92)$ & $72.11(10.41)$ \\
\hline & Education (years) $^{\mathrm{a}}$ & $13.12(3.94)$ & $13.63(4.05)$ & $12.22(3.80)$ \\
\hline \multirow[t]{2}{*}{ Gender ${ }^{\mathrm{b}}$} & Male & $16(64 \%)$ & $10(62.5 \%)$ & $6(66.7 \%)$ \\
\hline & Female & $9(36 \%)$ & $6(37.5 \%)$ & $3(33.3 \%)$ \\
\hline \multirow{4}{*}{ NYHA Class ${ }^{\mathrm{b}}$} & I & $3(12 \%)$ & $1(6.3 \%)$ & $2(22.2 \%)$ \\
\hline & II & $13(52 \%)$ & $8(50 \%)$ & $5(55.6 \%)$ \\
\hline & III & $5(20 \%)$ & $4(25 \%)$ & $1(11.1 \%)$ \\
\hline & IV & $1(4 \%)$ & $1(6.3 \%)$ & $0(0 \%)$ \\
\hline \multirow[t]{3}{*}{ Carer } & Age (years) ${ }^{a}$ & $67.24(11.42)$ & $67.19(11.20)$ & $67.33(12.49)$ \\
\hline & Education (years) $^{\mathrm{a}}$ & $12.64(2.80)$ & $13.00(3.01)$ & $12.00(2.40)$ \\
\hline & $\begin{array}{l}\text { Years known to each } \\
\text { other }^{\mathrm{a}}\end{array}$ & $45.92(14.74)$ & $44.88(15.02)$ & $47.78(14.93)$ \\
\hline Gender ${ }^{\mathrm{b}}$ & Females & $9(36 \%)$ & $6(37.5 \%)$ & $3(33.3 \%)$ \\
\hline
\end{tabular}

This article is protected by copyright. All rights reserved 


\begin{tabular}{|c|c|c|c|c|}
\hline & Males & $16(64 \%)$ & $10(62.5 \%)$ & $6(66.7 \%)$ \\
\hline \multirow{3}{*}{$\begin{array}{l}\text { Relationship to CHF } \\
\text { patient }^{b}\end{array}$} & Spouse/Partner & $21(84 \%)$ & $14(87.5 \%)$ & $7(77.8 \%)$ \\
\hline & Adult Child & $3(12 \%)$ & $2(12.5 \%)$ & $1(11.1 \%)$ \\
\hline & Friend & $1(4 \%)$ & $0(0 \%)$ & $1(11.1 \%)$ \\
\hline \multirow{5}{*}{ Employment Status $^{b}$} & Employed Full Time & $2(8 \%)$ & $2(12.5 \%)$ & $0(0 \%)$ \\
\hline & Employed Part Time & $4(16 \%)$ & $4(25 \%)$ & $0(0 \%)$ \\
\hline & Retired & $13(52 \%)$ & $8(50 \%)$ & $5(55.6 \%)$ \\
\hline & Home Duties & $4(16 \%)$ & $2(12.5 \%)$ & $2(22.2 \%)$ \\
\hline & Full Time Carer & $2(8 \%)$ & $0(0 \%)$ & $2(22.2 \%)$ \\
\hline
\end{tabular}

Parametric tests ( ${ }^{\mathrm{a}}$ t-tests) and non-parametric tests $\left({ }^{\mathrm{b}}\right.$ Chi-square analysis) indicated that there were no significant differences in demographic profiles among patients, their carer and dyadic care typology.

This article is protected by copyright. All rights reserved 
Table 2 Distribution of dyadic care types as measured by the Heart Failure Care Assessment Scale (HFCAS)

\begin{tabular}{|c|c|c|c|c|}
\hline \multirow[b]{2}{*}{ r } & \multirow{4}{*}{ Dyadic Care Type } & \multicolumn{3}{|c|}{$\mathrm{N}(\%)$} \\
\hline & & & Congruent & Incongruent \\
\hline \multirow{2}{*}{ Dyad Member } & & All Dyads & Dyads & Dyads \\
\hline & & & $\mathrm{N}=16$ & $\mathrm{~N}=9$ \\
\hline \multicolumn{5}{|l|}{ Patient } \\
\hline & Patient-Oriented & $9(36 \%)$ & $7(43.8 \%)$ & $2(22.2 \%)$ \\
\hline & Caregiver-Oriented & $1(4 \%)$ & $1(6.3 \%)$ & $0(0 \%)$ \\
\hline & Collaboratively-Oriented & $10(40 \%)$ & $5(31.3 \%)$ & $5(55.6 \%)$ \\
\hline & Complementary-Oriented & $5(20 \%)$ & $3(18.8 \%)$ & $2(22.2 \%)$ \\
\hline \multicolumn{5}{|l|}{ Caregiver } \\
\hline & Patient-Oriented & $9(36 \%)$ & $7(43.8 \%)$ & $2(22.2 \%)$ \\
\hline & Caregiver-Oriented & $4(16 \%)$ & $1(6.3 \%)$ & $3(33.3 \%)$ \\
\hline & Collaboratively-Oriented & $6(24 \%)$ & $5(31.3 \%)$ & $1(11.1 \%)$ \\
\hline & Complementary-Oriented & $6(24 \%)$ & $3(18.8 \%)$ & $3(33.3 \%)$ \\
\hline
\end{tabular}

This article is protected by copyright. All rights reserved 
Table 3 Patient outcome measures for congruent and incongruent dyads

\begin{tabular}{|c|c|c|c|c|c|c|c|}
\hline \multirow{2}{*}{ Measure (min - max scores) } & \multicolumn{2}{|c|}{ Congruent $(N=16)$} & \multicolumn{2}{|c|}{ Incongruent $(N=9)$} & \multirow{2}{*}{$\begin{array}{c}\text { Sig } \\
p\end{array}$} & \multicolumn{2}{|c|}{ Effect size } \\
\hline & $\operatorname{Median}(I Q R)$ & $\operatorname{Mean}(S D)$ & $\operatorname{Median}(I Q R)$ & $\operatorname{Mean}(S D)$ & & $r$ & $d$ \\
\hline \multicolumn{8}{|l|}{ DASS } \\
\hline Depression $(0-21)$ & & $4.7(4.2)$ & & $3.9(1.5)$ & 0.51 & & 0.25 \\
\hline Anxiety $(0-21)$ & $3.0(5.8)$ & & $3.0(6.0)$ & & 0.98 & -0.01 & \\
\hline Stress $(0-21)$ & $5.0(9.3)$ & & $2.0(3.0)$ & & 0.76 & -0.07 & \\
\hline Quality of life $(0-10)$ & $9.0(3.0)$ & & $8.0(2.0)$ & & 0.36 & -0.20 & \\
\hline \multicolumn{8}{|l|}{ Self-Care of HF (SCHFI) } \\
\hline Maintenance $(0-100)$ & & $71.1(10.8)$ & & $65.8(13.4)$ & 0.29 & & 0.43 \\
\hline Management $\dagger(0-100)$ & & $53.2(19.9)$ & & $57.5(10.4)$ & 0.60 & & -0.27 \\
\hline Confidence $(0-100)$ & $61.2(34.8)$ & & $66.7(25.0)$ & & 0.25 & -0.23 & \\
\hline \multicolumn{8}{|l|}{ Relationship Quality (RDAS) } \\
\hline Consensus & $13.0(2.0)$ & & $13.0(2.0)$ & & 0.45 & -0.16 & \\
\hline Satisfaction & $8.0(2.0)$ & & $7.0(1.0)$ & & 0.07 & -0.37 & \\
\hline Cohesion & & $11.3(4.1)$ & & $9.9(5.2)$ & 0.47 & & 0.29 \\
\hline Total $(10-59)$ & & $32.0(5.2)$ & & $28.5(7.3)$ & 0.18 & & 0.54 \\
\hline
\end{tabular}

This article is protected by copyright. All rights reserved 
$†$ Only includes participants reporting symptoms in the past month (congruent $\mathrm{N}=11$, incongruent $\mathrm{N}=4$ ).

Table 4 Carer outcome measures for congruent and incongruent dyads

\begin{tabular}{|c|c|c|c|c|c|c|c|}
\hline \multirow[t]{2}{*}{ Measure (min - max scores) } & \multicolumn{2}{|c|}{ Congruent $(N=16)$} & \multicolumn{2}{|c|}{ Incongruent $(N=9)$} & \multirow{2}{*}{$\begin{array}{c}\text { Sig } \\
p\end{array}$} & \multicolumn{2}{|c|}{ Effect size } \\
\hline & Median $(I Q R)$ & $\operatorname{Mean}(S D)$ & Median $(I Q R)$ & $\operatorname{Mean}(S D)$ & & $r$ & $d$ \\
\hline \multicolumn{8}{|l|}{ DASS } \\
\hline Depression $(0-21)$ & $2.8(2.1)$ & & $2.2(1.9)$ & & 0.53 & & 0.27 \\
\hline Anxiety $(0-21)$ & $0.0(1.8)$ & & $1.0(2.0)$ & & 0.39 & -0.20 & \\
\hline Stress ( & $3.0(4.5)$ & & $2.0(3.0)$ & & 0.72 & -0.07 & \\
\hline Quality of life $(0-10)$ & $9.0(3.0)$ & & $8.0(2.0)$ & & 0.36 & -0.20 & \\
\hline \multicolumn{8}{|l|}{ CRA $(1-5)$} \\
\hline (IoS) & & $2.7(0.8)$ & & $2.6(0.5)$ & 0.76 & & 0.15 \\
\hline (LoFS) & & $2.0(0.7)$ & & $2.3(1.0)$ & 0.33 & & 0.40 \\
\hline$(\mathrm{IoH})$ & & $1.8(0.6)$ & & $2.3(0.8)$ & 0.08 & & 0.72 \\
\hline$(\mathrm{IoF})$ & & $2.3(0.7)$ & & $2.6(0.6)$ & 0.28 & & 0.48 \\
\hline$(\mathrm{CE})$ & & $4.1(0.6)$ & & $4.1(0.4)$ & 0.99 & & 0.01 \\
\hline
\end{tabular}

$S D=$ standard deviation; $d=$ Cohen's $d ; I Q R=$ interquartile range; $r=\mathrm{Z} / \mathrm{sqrt}(\mathrm{N}) ; \mathrm{p}=$ significance value of either the Mann-Whitney $\mathrm{U}$ test or t-test;

This article is protected by copyright. All rights reserved 
DASS = Depression Anxiety Stress Scale; CRA = Caregiver Reaction Assessment; IoS = Impact on Schedule; LoFS = Lack of Family Support; $\mathrm{IoH}=$ Impact on Health; IoF = Impact on Finances; CE = Caregiver's Esteem.

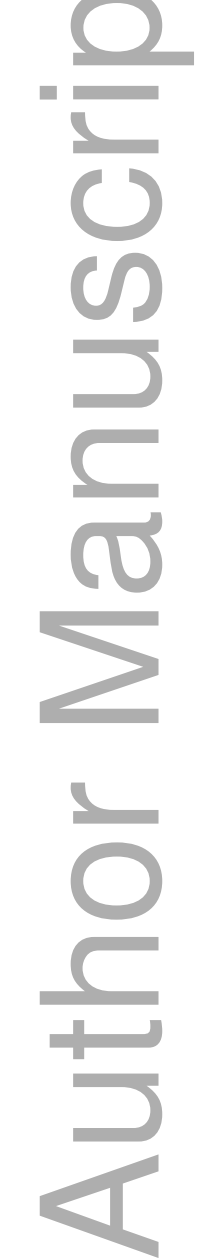

This article is protected by copyright. All rights reserved 


\section{University Library}

\section{- M M N E R VA A gateway to Melbourne's research publications}

Minerva Access is the Institutional Repository of The University of Melbourne

Author/s:

Cameron, J;Thompson, DR;Szer, D;Greig, J;Ski, CF

Title:

Dyadic incongruence in chronic heart failure: Implications forpatient and carer psychological health and self-care

Date:

2017-12-01

Citation:

Cameron, J., Thompson, D. R., Szer, D., Greig, J. \& Ski, C. F. (2017). Dyadic incongruence in chronic heart failure: Implications forpatient and carer psychological health and self-care. JOURNAL OF CLINICAL NURSING, 26 (23-24), pp.4804-4812. https://doi.org/10.1111/ jocn.13836.

Persistent Link:

http://hdl.handle.net/11343/293198 